\title{
Estudo de caso: 0 que Rafael Correa disse? Comparando a atenção política em 10 anos dos discursos do presidente equatoriano
}

\section{Pablo Ruiz Aguirre 1}

1 Universidad Internacional del Ecuador / Facultad de Jurisprudencia - Equador

\begin{abstract}
A "revolução cidadã" foi o projeto político realizado principalmente pelo ex-presidente da República do Equador, Rafael Correa Delgado, sob o paradigma do socialismo do século XXI entre 2007 e 2016. Esse projeto foi caracterizado por estabelecer uma nova agenda política no país, diferenciando-se do passado, concentrando-se em questões como reconhecimento de novos direitos, melhoria da educação, proposta de um novo modelo econômico e fortalecimento do governo e da soberania, entre outros. Nesse contexto, este trabalho tem como objetivo analisar a atenção política na agenda do ex-presidente da república, explicar por que algumas questões são mais importantes que outras e por que há variações nelas ao longo do tempo. Com base em uma estrutura conceitual que retira ideias da teoria da definição da agenda, a concentração da agenda política é medida através do índice de entropia de Shannon e as diferentes mudanças nele são explicadas como resultado de preferências, atritos institucionais e eventos externos. A análise é baseada em extensas bases de dados de 10 anos de discursos governamentais (presidência de Rafael Correa), codificados de acordo com a metodologia do Projeto de agendas comparativas (PAC). Até onde sabemos, este é o primeiro trabalho que aplica essa metodologia no Equador.
\end{abstract}

Palavras-chave: agenda; agendas temáticas; discursos executivos; atenção política; Rafael Correa.

\section{Estudio de caso: ¿qué dijo Rafael Correa? Comparando la atención política en 10 años de discursos del presidente ecuatoriano}

La "revolución ciudadana" fue el proyecto político ejecutado principalmente por el expresidente de la República del Ecuador, Rafael Correa Delgado, bajo el paradigma del socialismo del siglo XXI, entre 2007 y 2016 . Este proyecto se caracterizó por establecer una nueva agenda política en el país, diferenciándose de las pasadas, enfocándose en temas como el reconocimiento de nuevos derechos, mejora de la educación, propuesta un nuevo modelo económico y el fortalecimiento del gobierno y la soberanía entre otros. Bajo este contexto, este trabajo tiene como objetivo analizar la atención política de la agenda del expresidente de la república, explicar por qué algunos temas son más importantes que otros y por qué hay variaciones en ellos a lo largo del tiempo. Con base en un marco conceptual que toma ideas de la teoría del establecimiento de la agenda, se mide la concentración de la agenda política a través del índice de entropía de Shannon y se explican los diferentes cambios en ella a raíz de las preferencias, las fricciones institucionales y los eventos externos. El análisis se basa en extensas bases de datos sobre 10 años de discursos del gobierno (presidencia de Rafael Correa), que están codificados de acuerdo con la metodología del Proyecto de Agendas Comparadas (PAC). Por lo que conocemos, este es el primer trabajo que aplica esta metodología en Ecuador.

Palabras clave: establecimiento de agenda; agendas temáticas; discursos presidenciales; atención política; Rafael Correa. 


\title{
Case study: what did Rafael Correa say? Comparing political attention across 10 years of the Ecuadorian president's discourses
}

\begin{abstract}
The "citizen revolution" was a political project executed mainly between 2007 and 2016 by the former president of the Republic of Ecuador, Rafael Correa Delgado, under the paradigm of $21^{\text {st }}$ century socialism. The main characteristic of this project was to introduce a new political agenda to the country that was differentiated from past agendas, by focusing on issues such as the recognition of new rights, improvements to education, instituting a new economic model, and strengthening government and sovereignty, among others. Under this context, this work aims to analyze the political attention of the ex-president, explaining why some issues are more important than others, and why they varied over time. Based on a conceptual framework that takes ideas from the agenda-setting theory, the areas on which the political agenda concentrates are measured by the Shannon entropy index, and its various changes are explained as the results of preferences, institutional factors, and external events. The analysis is based on extensive database analyses of 10 years (covering Rafael Correa's presidency) of government speeches, which are coded according to the methodology of the Comparative Agendas Project (CAP). To the best of our knowledge, this paper is the first work to apply the CAP methodology in Ecuador.
\end{abstract}

Keywords: agenda setting; issue agendas; executive speeches; political attention; Rafael Correa.

\section{INTRODUÇÃO}

Uma agenda política é composta de um conjunto de tópicos, situações e problemas que uma sociedade considera essenciais em determinado momento e local (Kingdon, 1984). Muitas desses tópicos são pautadas pelos legisladores, alguns são promovidas pela mídia, e outros são levados ao debate pelas autoridades do poder executivo. Particularmente no último caso, a pergunta que se coloca é: como um presidente pode definir a agenda política em um mundo onde a informação é abundante e é impossível imaginar que tudo, ao mesmo tempo, possa ser considerado essencial? Uma das formas de compreender como se dá a definição das prioridades na agenda política é estudando os discursos oficiais do chefe de Estado. Entretanto, pode não ser tão claro como esse conjunto de dados deve ser analisado, e a resposta para tal desafio está em abordar o conteúdo a partir de uma perspectiva do agendamento (agenda-setting), ou seja, o estudo de quais tópicos conseguem entrar na agenda política e por quê (Bachrach \& Baratz, 1962; Cobb \& Elder, 1980; Downs, 1972; Kingdon, 1984; McCombs \& Shaw, 1972; Schattschneider, 1960). O Comparative Agendas Project (CAP) "permite que pesquisadores, estudantes, formuladores de política pública e a mídia explorem as tendências na elaboração de políticas ao logo do tempo e entre países" (www.comparativeagendas.net, tradução nossa). O CAP teve início nos EUA, disseminando-se por países europeus (John, 2006) e, recentemente, ampliou seu alcance para abarcar os países latino-americanos, incluindo Brasil, Colômbia e Equador, proporcionando novos caminhos para futuras pesquisas comparativas.

Esse artigo traz, até onde tenho conhecimento, a primeira aplicação da metodologia do CAP no estudo da política equatoriana. O trabalho analisa a atenção política dispensada pela agenda do ex-presidente Rafael Correa Delgado para explicar por que alguns tópicos são priorizados e recebem mais atenção do que outros, bem como por que ocorre variação ao longo do tempo. Foram analisados os discursos do ex-presidente, proferidos entre os anos de 2007 e 2016, sendo que três dessas manifestações são discursos de posse e as demais refletem momentos de prestação de contas. A diferença nos tipos de discurso será abordada mais adiante no artigo. $\mathrm{O}$ registro dos discursos de Rafael Correa constitui a mais longa série de dados do gênero conhecidos no Equador, compreendendo 10 discursos em 10 anos e somando 3.297 unidades de análise (quasi-sentenças). 
A primeira questão a ser explorada é: Quais foram os tópicos relevantes na agenda política do presidente equatoriano Rafael Correa? A abordagem do agendamento oferece explicações não convencionais para as variações de como e por que os temas entram e saem da pauta, para além das simples preferências políticas (Baumgartner, Jones, \& Wilkerson, 2011). A priorização dos tópicos pode transcender o foco dado no conteúdo dos discursos, podendo refletir uma estratégia, um cálculo político, ou envolver o conhecimento de questões específicas que sustentam fatores determinantes para a agenda de políticas públicas. Assim, a segunda questão é por que as agendas políticas mudam ao longo dos anos. O pressuposto é que uma agenda e suas mudanças podem ser explicadas por preferências políticas, fatores institucionais, eventos com focos particulares, e novos fluxos de informação.

Vários estudos similares usando uma perspectiva comparativa já foram realizados, como a pesquisa sobre a agenda política australiana por meio da análise dos discursos dos governadores-gerais. Tal investigação identificou que o discurso dessas autoridades não é incremental, e que as mudanças de agenda ocorrem como resposta a novos eventos (Dowding, Hindmoor, Iles \& John, 2010). No Reino Unido, um estudo sobre a 'Fala do Trono' (The Speech from the Throne) observou a ênfase seletiva dada a determinados temas de acordo com a influência dos partidos representados no parlamento, também apontando quando houve incorporação de outros tópicos na agenda em virtude de fatores exógenos. Os autores identificaram que o discurso é afetado por choques externos e que reflete os pontos fortes dos tópicos de interesse dos maiores partidos políticos da Grã-Bretanha (Jennings, Bevan, \& John, 2011). Outras pesquisas comparativas analisando discursos no Reino Unido, na Dinamarca e nos Países Baixos procuraram determinar se uma mudança no partido ocupando o governo resultaria em uma mudança em sua agenda política. Esses estudos demonstraram que o fator 'eleições' não consegue explicar muito sobre mudanças na agenda política do poder executivo (Mortensen et al., 2011). Já uma análise dos efeitos que as funções centrais do governo produzem sobre a diversidade das agendas executivas, observando vários países europeus e os EUA, mostrou que os tópicos nas agendas tendem a se concentrar ou se relacionar com as funções clássicas do estado, tais como governo e administração pública, economia e defesa (Jennings et al., 2011). Por fim, diversos autores se concentraram na evolução da priorização de temas, tanto nos EUA quanto na Espanha. Eles verificaram que as variações na concentração da agenda coincidem com alguns eventos específicos (Chaqués-Bonafont, Palau, Muñoz, \& Wilkerson, 2008).

O presente trabalho traz uma contribuição claramente empírica, verificando pela primeira vez no Equador algumas das teorias e hipóteses já levantadas pela comunidade de pesquisa que atua em torno do CAP, buscando também responder questões de pesquisa mais específicas do contexto. Os resultados preliminares mostram que a concentração da agenda coincide efetivamente com as funções tradicionais do Estado e mostra uma preferência por questões 'não conservadoras', tais como direitos civis e das minorias. Entretanto, os resultados sugeriram uma característica peculiar no caso equatoriano que não foi identificada até agora em outros estudos: a emergência de uma grande concentração de atenção do executivo no que aqui chamo de "retórica". Essa evidencia é baseada em uma unidade de análise (quasi-sentença) que não pôde ser codificada de acordo com a metodologia proposta porque não incluía um conteúdo de política pública, mas puramente retórica, formada por frases motivacionais, histórias e metáforas. $\mathrm{O}$ fenômeno é interessante porque levanta questões não consideradas pelos estudos atuais da agenda como, por exemplo, se isso ocorre com frequência nos regimes presidenciais latino-americanos, ou se é algo que ocorre somente na América Latina. Ainda, seria esse um tipo de conteúdo relacionado a regimes populistas? 
O artigo está separado em cinco partes, incluindo essa introdução. Nas próximas seções serão apresentadas a literatura existente em relação ao caso tratado, seguida por uma exposição dos dados e da metodologia adota. A quarta seção é dedicada a explicar as mudanças na priorização dos tópicos na agenda presidencial, levando a última parte onde apresento conclusões preliminares.

\section{CONTEXTO DA TEORIA DO AGENDAMENTO}

Os governos geralmente recebem uma infinidade de informações, trazidas a público na tentativa de definir uma determinada realidade e abrir espaço a algum tópico na competitiva agenda política. A abordagem do agendamento procura estudar as questões que conseguem acessar esse espaço, como o conquistam e por quê. Ao longo das últimas décadas, tais fenômenos têm sido amplamente analisados, tanto prática quanto teoricamente (Bachrach \& Baratz, 1962; Baumgartner \& Jones, 2010; Cobb \& Elder, 1980; Downs, 1972; Jones \& Baumgartner, 2005; Kingdon, 1984; McCombs \& Shaw, 1972; Schattschneider, 1960).

O processo político não envolve necessariamente ordem e planejamento, sendo geralmente mais bem explicado por meio de sua desordem e da ausência de planos. As preferências constituem apenas uma variável na tentativa de explicar os resultados políticos (Baumgartner et al., 2011; GreenPedersen, 2007; Walgrave, Varone, \& Dumont, 2006), ou seja, a atenção dispensada aos diversos tópicos, observada em base aos discursos presidenciais, é impulsionada não apenas pelas preferências dos partidos influentes, mas também por fatores institucionais, pela chegada de novos fluxos de informação e por mudanças repentinas, como, por exemplo, uma crise econômica (Chaqués-Bonafont, Baumgartner, \& Palau, 2015). Consequentemente, essas três variáveis explicativas da agenda política - preferências políticas, fatores institucionais e eventos inesperados - serão analisadas e relacionadas, do ponto de vista teórico, para explicar a agenda política equatoriana.

Primeiro, como muitos autores já enfatizaram, as preferências políticas são importantes para explicar por que os assuntos entram na agenda (Boix, 1998; Canes-Wrone, 2001), e no caso do Equador, elas podem ser observadas nos discursos do chefe de Estado. Essas falas, portanto, podem ser tratadas como uma fonte de informação sobre a agenda política do executivo (Breeman et al., 2009; Jennings \& John, 2009; Jennings et al., 2011; John, Larsen, \& Liu, 2006; John, Jennings, \& Bevan, 2010; Mortensen et al., 2009). Ainda, quais são essas preferências que os presidentes expressam em um discurso? Um político pode usar um discurso para diversos fins, como assumir compromissos públicos, estabelecer novas prioridades ou destacar temas já considerados prioritários. Os discursos podem servir para responder a problemas públicos antes, durante e depois de uma campanha eleitoral, ou para persuadir o eleitorado. Consequentemente, refletem não somente as prioridades políticas reais, mas também as preferências partidárias. Assim, alguns tópicos podem ser destacados através da fala do chefe do executivo para dar uma ilusão de interesse ou prioridade - são os temas que o político prefere expressar -, enquanto outros podem ser ignorados devido a cálculos políticos - ou seja, temas que o político prefere não discutir (Dowding et al., 2010).

Neste sentido, as políticas são fundamentadas em preferências partidárias (ou do ator). Essa conclusão é corroborada pelos estudos sobre o engajamento dos públicos em determinados temas (issue ownership), que afirmam, por exemplo, que os partidos tentam capitalizar em uma agenda, atuando sobre tópicos nos quais são mais competentes (Budge \& Hofferbert, 1990; Klingemann, Hofferbert, \& Budge, 1994). Além disso, um grande número de estudos na comunidade do Comparative 
Agendas Project (CAP) tem usado a issue ownership theory para explicar porque as elites políticas prestam atenção a alguns temas e não a outros (Green \& Jennings, 2012; Green \& Jennings, 2019; Green-Pedersen \& Mortensen, 2010). Essa teoria foi originalmente desenvolvida para explicar por que os partidos políticos prestam atenção a uma ou outra questão durante as campanhas eleitorais, e considera que eles enfatizam as questões onde são conhecidos por ter mais competência e nas quais seus oponentes são reconhecidos como menos habilidosos (Budge \& Farlie, 1983; Petrocik, 1996). De acordo com as premissas dessa teoria, é de se esperar que os partidos de esquerda se concentrem mais em questões relacionadas ao bem-estar, igualdade de direitos e meio ambiente, onde são percebidos pelo público como tendo um melhor desempenho, enquanto os partidos de direita devem prestar mais atenção a questões como economia, impostos e crime, onde têm uma reputação de bom desempenho. A partir desse contexto, surge uma questão: Será que essas ideias podem ser aplicadas ao estudo da agenda de um presidente em um sistema presidencial?

Em outros casos, nos estudos da agenda política australiana, por exemplo, o discurso foi determinado como sinal das intenções políticas de um novo governo (Dowding et al., 2010). Será que os discursos de Rafael Correa, no Equador, expressam essa característica? Será que seus discursos manifestam uma ênfase seletiva, ou esse 'engajamento' - issue ownership - (Budge \& Farlie, 1983; Carmines \& Stimson, 1989; Petrocik, 1996), onde seu partido “Alianza País” promove questões das quais pode se beneficiar (Budge \& Farlie, 1983) por gozar de boa reputação? (Petrocik, 1996).

Em relação a esse tema, estudos das agendas políticas no Reino Unido por meio da "Fala do Trono", por exemplo, identificaram que o papel do discurso no agendamento reflete os pontos fortes dos principais partidos políticos. Isso significa que os governos conservadores tendem a dar menos atenção aos direitos civis e às questões das minorias, questões sociais e operações governamentais, mas, em contrapartida, dedicam maior cuidado a política externa, por exemplo (Jennings et al., 2011). A partir dessas ideias - e porque os discursos são agendas caracterizadas pela alta exposição usada para enviar mensagens ao eleitorado - pode-se esperar que o presidente do Equador enfatizaria questões que são de interesse dos eleitores do partido no poder. Isso significa que, tendo sido eleito como presidente da esquerda - ou do "socialismo do século 21" (como o próprio ex-presidente qualificou) - e precisando responder a seus eleitores, ele deveria destacar tópicos como a garanta de direitos, política social e educação. Então, será que Correa dá de fato mais atenção aos direitos civis e das minorias, a questões sociais e aos processos de governo e da administração público do que às questões de política externa, por exemplo, como sugerido por Jennings et al. (2011)?

A segunda variável das três que orientam a apresentação dessa seção é a dos fatores institucionais. Como visto acima, a agenda política não depende exclusivamente das preferências do presidente, sejam elas partidárias ou ideológicas. Fatores institucionais impõem limitações significativas aos planos e ao desempenho dos atores envolvidos nos processos de elaboração de políticas públicas (Baumgartner \& Jones, 2015). Assim, as preferências presidenciais são importantes. Os discursos transmitem as mensagens aos eleitores e espera-se que os temas que dão aos partidos incumbentes uma maior vantagem eleitoral sejam enfatizados. Entretanto, independentemente das preferências, alguns temas devem ser obrigatoriamente abordados por qualquer presidente. A literatura mostra que as funções-chave do Estado são um fator determinante para explicar o quão dispersa deve ser a atenção do governo (Kingdon, 1984). Além disso, algumas questões são levadas mais a sério por um ou outro governo (Jennings et al., 2011). Essas características podem ser delineadas tendo por referência às teorias clássicas do Estado (Hobbes, 1651; Locke, 1689; Rousseau, 1762), nas quais 
seus compromissos centrais são proteger fronteiras, administrar a política externa e garantir o bemestar geral de seu povo, além da manutenção do aparato Estatal. Ainda, alguns estudos destacam que a maioria das agendas governamentais está inclinada a se concentrar na economia, defesa e política externa (Cohen, 1999; Edwards \& Barrett, 2000).

Da mesma forma, existem algumas funções executivas centrais que têm a capacidade de concentrar a agenda. Assim, uma análise comparativa da diversidade de assuntos nas agendas executivas de vários países europeus e dos Estados Unidos durante o período pós-guerra, mostrou que as agendas governamentais tendem a se concentrar em assuntos como economia, governo e administração pública, defesa e política externa, todos temas considerados como funções centrais do Estado. O estudo também sugere que quando as funções centrais do governo são menos importantes na agenda, os executivos a podem diversificar; mas quando essas funções centrais assumem papel de destaque na agenda há uma maior concentração da atenção justamente nelas (Jennings et al., 2011). A pergunta que se coloca aqui é se essa mesma dinâmica se repete no Equador, considerando que o país tem uma estrutura governamental diferente dos sistemas parlamentares europeus e, é claro, tem uma realidade histórica e contextual diferente em comparação com os países do Norte Global, como os EUA.

A terceira variável destacada aqui diz respeito a eventos não planejados e fluxos de novas informações, que são elementos significativos para compreender como e por que novos temas ganham espaço na agenda política (Baumgartner \& Jones, 2010, 2015; Chaqués-Bonafont et al., 2015; Kingdon, 1984). Problemas ambientais, catástrofes naturais, escândalos de corrupção, crises econômicas, escândalos políticos ou qualquer nova publicação ou informação que não havia sido inicialmente considerada, podem mudar drasticamente a agenda política do governo. Assim, o terremoto que ocorreu na costa equatoriana em abril de 2016, por exemplo, mudou profundamente não só a agenda política do governo do ponto de vista simbólico, mas também sua agenda substantiva.

É importante enfatizar que questões latentes podem subir ao topo da agenda política, possivelmente devido a crises ou ao surgimento de novas situações (Baumgartner \& Jones, 2010; Baumgartner, Jones, \& MacLeod, 1998; Jones \& Baumgartner, 2005; Jones, Sulkin, \& Larsen, 2003). Nessa linha, estudos dos discursos dos governadores gerais na Austrália revelaram que as agendas políticas poderiam ser separadas das questões estabelecidas nos discursos dessas autoridades de forma cada vez mais clara, à medida que se sucedem diversos eventos (Dowding et al., 2010). Será que isso também ocorre no Equador? Ou seja, será que houve diferença entre o conteúdo dos discursos do ex-presidente do Equador em relação a agenda pública eventualmente modificada em virtude de eventos externos ou não planejados ocorridos em algum ano específico?

Outras pesquisas consideram que a função da agenda executiva é responder a informações ou choques externos, como guerras ou emergências constitucionais (Jennings et al., 2011). Assim, a inclusão de temas passa a ser uma nova informação a ser considerada na tomada de decisão (Jones \& Baumgartner, 2005), mostrando que os choques externos controlam a duração do discurso, tipicamente o diminuindo. Isso significa que eventos exógenos podem orientar o foco de atenção ou sua concentração em um discurso. Mas será que isso é verdade no caso do Equador? Os eventos externos chegaram a mudar a agenda política expressa nos discursos do presidente Correa?

Em síntese, as causas de aumento ou diminuição da atenção dedicada pelo governo a um ou mais tópicos não têm necessariamente uma única variável explicativa, mas sim múltiplas variáveis 
que podem ou não existir simultaneamente. Será que preferências políticas, fatores institucionais e eventos externos ajudaram a construir a agenda executiva do Equador durante o mandato de 10 anos do ex-presidente Rafael Correa? As perguntas feitas ao longo dessa seção serão respondidas positiva ou negativamente a seguir.

\section{DADOS E METODOLOGIA}

Do ponto de vista do agendamento, os discursos oficiais do chefe do executivo possuem alguns atributos interessantes. Um presidente que faz um discurso oficial fala em nome do governo e do Estado. No regime presidencial equatoriano, o presidente fala ao país como chefe de estado e de governo, e a mídia cobre tais discursos como grandes eventos que estabelecem a agenda pública. Portanto, após analisar as informações atuais para determinar as questões mais importantes e justificar esse julgamento, os discursos do presidente devem ser escritos para explicar quais as prioridades na agenda do executivo.

O presidente do Equador pode proferir dois tipos de discursos: um discurso de posse, realizado após vencidas as eleições; ou um discurso anual de prestação de contas, fazendo um balanço do progresso das atividades do governo no período. Estes tipos de discursos são legalmente apoiados pela Constituição de 2008, que especifica que o executivo, para obedecer à lógica de controle e equilíbrio, tem duas atribuições (Artigo 147): "São atribuições e deveres do Presidente da República, além de outras determinadas por lei: a) Apresentar à Assembleia Nacional, no momento de sua posse, as diretrizes fundamentais das políticas e ações que desenvolverá durante seu exercício; b) Apresentar anualmente à Assembleia Nacional o relatório de realizações em base ao Plano Nacional de Desenvolvimento e apresentar os objetivos do governo para o ano seguinte". Esse estudo aborda ambos os tipos de discurso, analisando três de posse e sete de prestação de contas.

O exame das agendas executivas comunicadas nos discursos anuais no Equador foi conduzido no âmbito do Ecuadorian Policy Agendas Project, e foi realizado a partir das transcrições completas, separando o conteúdo em unidades de análise (quasi-sentenças). A codificação foi realizada tendo por base a estrutura de codificação de conteúdo de políticas públicas criada pelo Spanish Policy Agendas Project (https://q-dem.com/es/) dadas as afinidades linguísticas, e seguindo o modelo original de codificação criado por Baumgartner e Jones (https://www.comparativeagendas.net/) para investigar o fenômeno do agendamento nos EUA. Um livro de código adaptado para o Equador foi criado de acordo com essas mesmas referências, garantindo que o projeto possa estabelecer comparações com os demais países participantes do CAP.

O sistema de codificação equatoriano inclui categorias para os principais tópicos de políticas públicas (24) e para diferentes subtópicos (247) dentro de cada uma dessas categorias (o Quadro 1 mostra os códigos dos tópicos principais). O projeto criou uma versão nacional do livro de códigos inicial feito no âmbito do CAP, mantendo as categorias originais, e acrescentando um novo código (9) relacionado ao modelo de desenvolvimento "buen vivir" (ou "bem viver") do Equador, além de alguns outros subcódigos para acomodar a realidade do país. Ainda, durante o processo de codificação foi considerado o código "retórica", dando conta de uma unidade de análise que não foi possível ser codificada a partir da metodologia proposta. 


\section{QUADRO 1 AGENDA POLÍTICA: 24 CÓDIGOS DOS TÓPICOS PRINCIPAIS}

\author{
1. Macroeconomia \\ 2. Direitos e liberdades civis e das minorias \\ 3. Saúde \\ 4. Agricultura \\ 5. Trabalho \\ 6. Educação e Cultura \\ 7. Meio-Ambiente \\ 8. Energia \\ 9. Bem viver \\ 10. Transportes \\ 12. Políticas Internas e Justiça \\ 13. Políticas Sociais \\ 14. Habitação e Desenvolvimento Comunitário \\ 15. Comércio e Setor Financeiro \\ 16. Defesa \\ 17. Pesquisa, Tecnologia e Comunicação \\ 18. Comércio Exterior \\ 19. Política Externa \\ 20. Governo e Administração Pública \\ 21. Terras Públicas \\ 23. Cultura \\ 27. Clima \\ 29. Esportes \\ 30. Notificação de mortes
}

Fonte: Elaborado pelo autor baseado no livro de código do Comparative Agendas Project (https://www.comparativeagendas.net/).

Embora o código "retórica" não tenha sido observado na literatura sobre agendamento, ele foi mantido aqui por três razões. Primeiro, o processo de codificação resultou em temas no nível de quasi-sentença que não puderam ser codificados em nenhum dos tópicos oferecidos pela metodologia, uma vez que não se tratavam de conteúdo político - tais como unidades de análise onde o ex-presidente começou contando uma anedota ou terminou um discurso reconhecendo sua equipe ou reiterando seu amor por sua família. Em segundo lugar, esse código obteve a maior porcentagem de atenção entre todos os discursos. Mais do que qualquer outro assunto, mesmo aqueles considerados de maior 
importância, tais como governo e administração pública, economia ou direitos e liberdades. A terceira razão, e a mais relevante, é a lógica que pode ser encontrada por trás de seu uso.

Como mencionado, os discursos foram codificados em unidades de análise de quasi-sentença, ou seja, uma "declaração política", uma manifestação de uma única ideia ou questão política, mas não necessariamente uma frase inteira (Volkens, 2002). Esse componente de análise é tipicamente identificado com base no uso de pontuação e conjunções. As transcrições dos discursos foram codificadas às cegas por dois pesquisadores da equipe do Ecuadorian Policy Agendas Project, que primeiro determinaram se cada quasi-sentença continha algum conteúdo de política e depois atribuíram a elas códigos de tópicos principais e de subtópicos. Esse sistema resultou em uma concordância de intercodificador de aproximadamente $90 \%$ na maioria dos anos. Os codificadores resolveram as dissemelhanças residuais através de debate, e o líder do projeto tomou a decisão final quando os codificadores não conseguiram chegar a um acordo. Esse procedimento de codificação gerou a mais longa série de dados conhecidos no Equador: 10 discursos de 2007 a 2016, consistindo de 3.297 unidades de análise. Como os discursos têm durações diversas, o destaque de cada tópico foi determinado não pelo número de unidades de análise atribuído a ele, mas pela proporção da presença dos tópicos em cada discurso (Dowding et al., 2010).

Para verificar se os discursos do presidente enfocam questões específicas como direitos ou questões relacionadas às funções tradicionais do estado, é necessário medir como se fragmenta a atenção em cada discurso. Como resultados introdutórios, obtivemos a porcentagem de atenção para cada tópico, levando em conta sua frequência em meio a todas as unidades de análise. Da mesma forma, foi obtida a atenção média de cada tópico em relação aos 10 anos de discursos. Ainda, o estudo considerou o indicador de entropia (H) de Shannon (Shannon, 1948) que, de acordo com (Jennings et al., 2011), ajuda a entender as diferentes gradações de informação, bem como a informação média por mensagem, medido a atenção do executivo. Um discurso do chefe do executivo que se concentra somente em um ou dois tópicos significa que a atenção do governo é dedicada intensamente a eles, enquanto que uma manifestação que expressa vários tópicos indica níveis menores de dedicação do governo a cada um deles. Aplicado ao caso em tela, a entropia $(\mathrm{H})$ mede a probabilidade de que o governo concentre a atenção nas questões observadas no discurso de Rafael Correa. Quando apenas um tópico é abordado, a probabilidade de que ganhe atenção é presumida como 1; quando são abordados 25 , a probabilidade de que o governo se concentre em qualquer um deles é de 0,05 . Em outras palavras, se a atenção do governo fosse igualmente distribuída por todos os tópicos, então $4 \%$ de sua atenção seria dada um deles. A entropia $(\mathrm{H})$ de Shannon faz uma interpretação probabilística, onde a entropia de uma estrutura é medida pela distribuição de anotações por várias categorias nominais discretas - nesse caso os itens codificados. Quanto maior a entropia, maior a incerteza sobre qual é o tópico em que o governo vai dedicar mais atenção (Boydstun, Bevan, \& Thomas, 2014). A entropia é calculada da seguinte forma:

$$
\mathrm{H}=(-1) \sum_{i=1}^{n} \mathrm{p}\left(\mathrm{x}_{\mathrm{i}}\right) \ln \left(\mathrm{p}\left(\mathrm{x}_{\mathrm{i}}\right)\right)
$$

onde a pontuação da entropia $(\mathrm{H})$ é a soma negativa de todos os tópicos relativos à probabilidade $\mathrm{p}(\mathrm{x})$ de que um objeto $\mathrm{x}$ (nesse caso, uma unidade de análise/declaração de política no discurso do presidente) se enquadre em um tópico i, multiplicada pelo registro natural dessa probabilidade. Logs de zero não podem ser considerados; portanto, assume-se que $06 \ln (0)^{1 / 4} 40$ para tópicos onde não 
houve unidade de análise/declaração de política num determinado ano. A pontuação de entropia mais extrema possível para os 25 códigos de tópicos principais é igual ao log natural de 25 (ou seja, 3.2188). Uma pontuação de entropia igual a 0 indica que a atenção está concentrada em um único tópico, enquanto uma pontuação de 3.2188 indica que a atenção está igualmente espalhada por todos os 25 tópicos principais de tal forma que cada assunto supostamente recebe $4 \%$ da atenção, ou $4 \%$ de chance de ser abordado pelo governo (Boydstun, et al., 2014).

\section{RESULTADOS}

O que se pode esperar dos dados coletados? Primeiro, em relação às preferências, o ex-presidente sempre se descreveu como uma pessoa de esquerda, como um defensor "do socialismo do século XXI". Portanto, o esperado é que seu governo dedicaria mais atenção a questões políticas relacionadas a essa tendência ideológica, por exemplo, direitos civis e das minorias, em detrimento de tópicos como política externa. Para avaliar isso, a porcentagem de atenção em cada ano dos discursos foi ilustrada nos gráficos da Figura 1, com os tópicos principais separados cada qual em um gráfico. Pode-se perceber como os tópicos receberam atenção, individualmente, ao longo dos anos, e evidenciam-se as diferenças entre eles. Dois tópicos principais não foram considerados: primeiro, ficou de fora a cultura (que envolve subtópicos como cinema, teatro, música e dança e publicação de livros), pois não recebeu uma porcentagem válida de atenção. O outro tópico foi esportes, que obteve apenas a porcentagem mínima de atenção $(0,5)$ durante 2014. O código "retórica", identificado ao longo da análise e que envolve histórias narrativas, frases ou poemas que não têm conteúdo político, foi considerado e consta como o primeiro gráfico da Figura 1.

FIGURA 1 PROPORÇÃO DE ATENÇÃO DISPENSADA PELO EXECUTIVO AOS TÓPICOS PRINCIPAIS DE POLITICAS

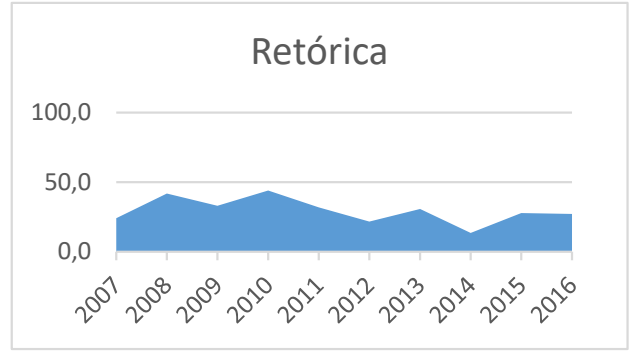

2. Direitos e liberdades civis e das minorias

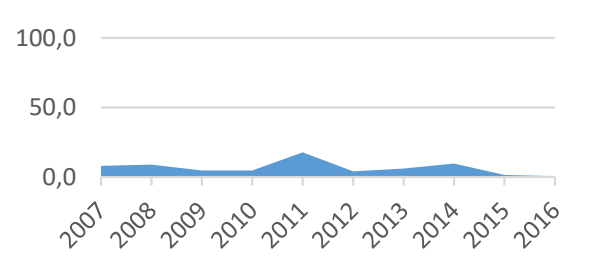

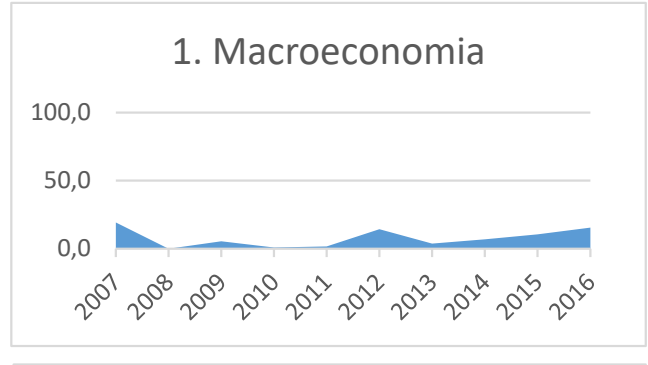

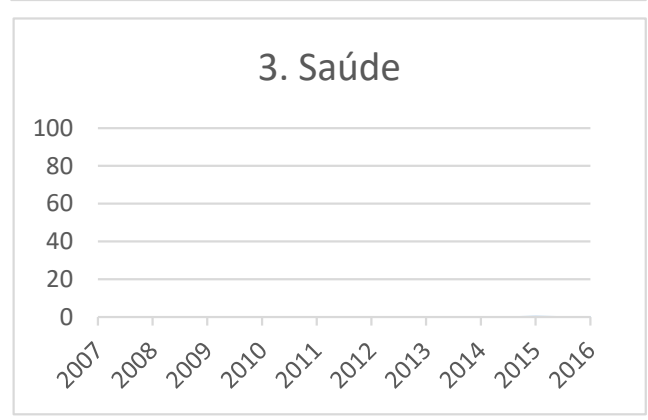

Continua 
RAP

Estudo de caso: 0 que Rafael Correa disse? Comparando a atenção política em 10 anos dos discursos do presidente equatoriano
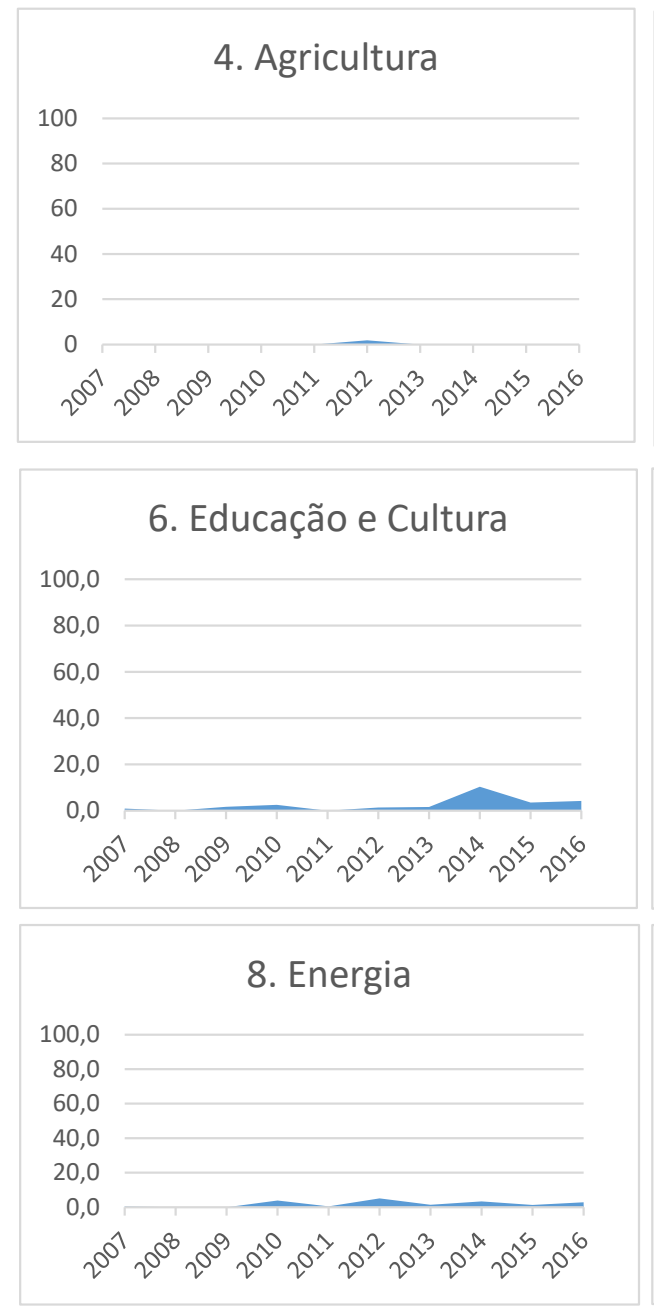

10. Transportes

100

50

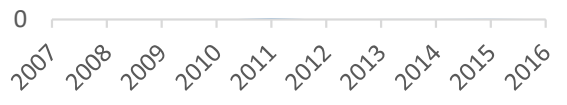

13. Política Social

100,0

50,0

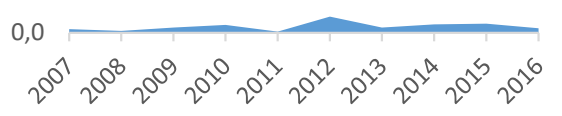

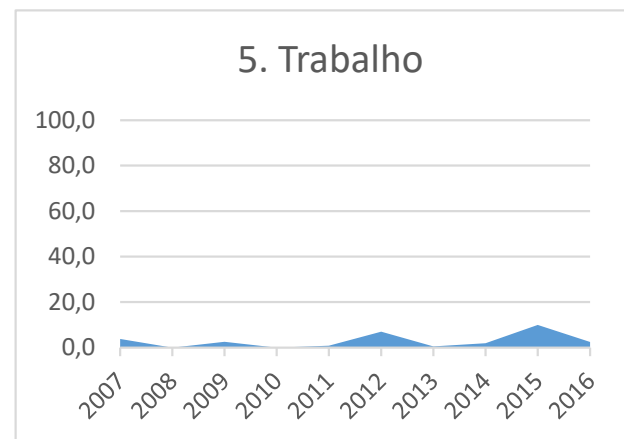

7. Meio-Ambiente

100,0

80,0

60,0

40,0

20,0

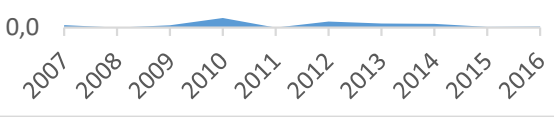

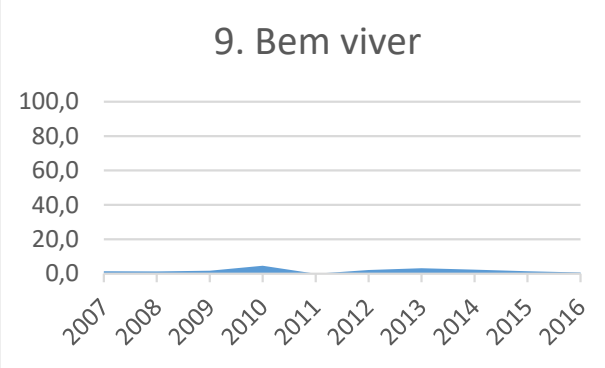

12. Políticas Internas e Justiça

100,0

50,0

0,0

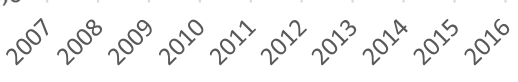

14. Habitação e

Desenvolvimento Comunitário

100,0

50,0

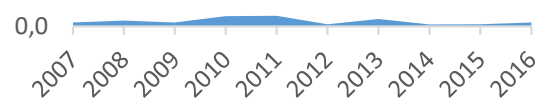

Continua

Revista de Administração PÚBlica ｜ Rio de Janeiro 54(6):1546-1564, nov. - dez. 2020

1556 
RAP

Estudo de caso: 0 que Rafael Correa disse? Comparando a atenção política em 10 anos dos discursos do presidente equatoriano
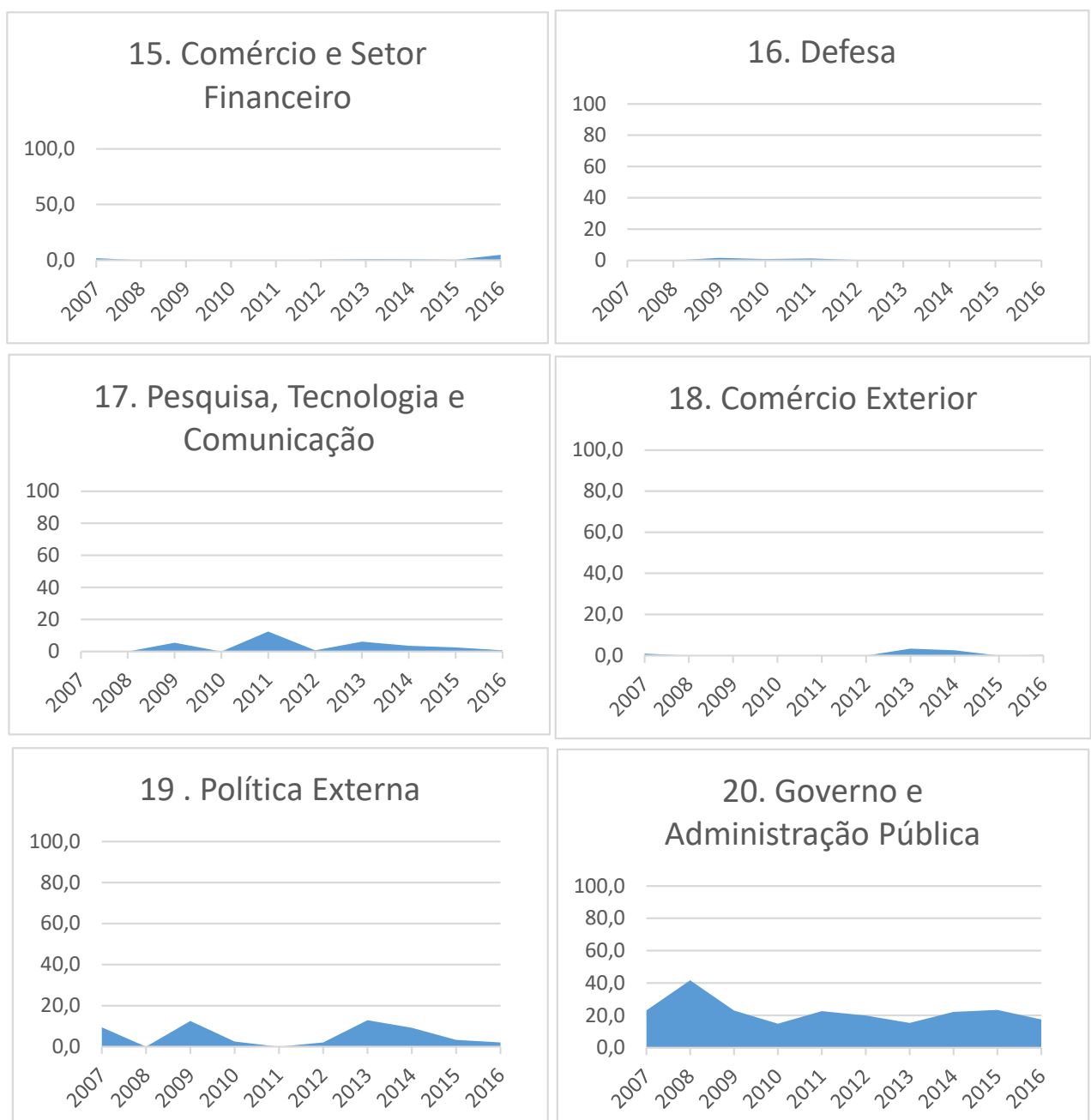

20. Governo e

100,0

18. Comércio Exterior

80,0

60,0

40,0

20,0

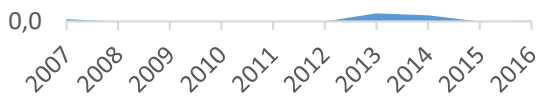

21. Terras Públicas

100

80

60

40

20

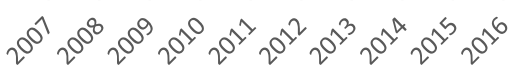

27. Clima

100

80

60

40

20

0

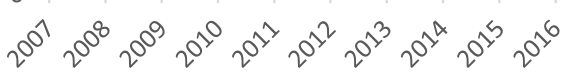

30. Notificação de mortes

100

80

60

40

20

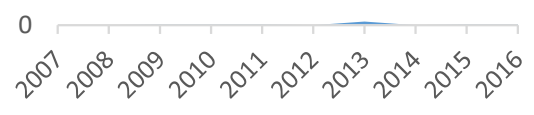

Fonte: Elaborada pelo autor em base aos discursos de Rafael Correa entre 2007 e 2016.

Revista de Administração PÚBlica ｜ Rio de Janeiro 54(6):1546-1564, nov. - dez. 2020

1557 
Alguns dos tópicos (Tabela 1) se destacaram nessa análise, considerando os percentuais médios de atenção que receberam ao longo dos 10 anos. Essas questões são a política social (4,1\%), política interna e justiça (4,5\%), política externa $(5,4 \%)$, direitos $(6,6 \%)$, economia $(7,8 \%)$ e governo e administração pública (22,3\%). O código "retórica" apresenta a maior porcentagem (29,6\%).

Esses resultados mostram que aproximadamente $50 \%$ da agenda política do presidente é usada em retórica e assuntos governamentais, e existe uma abismal lacuna entre esses e os outros assuntos aos quais o chefe do executivo prestou atenção. Considerando a expectativa inicial, em média, a agenda executiva dedica menos atenção à política externa (19) e mais às questões de direitos civis e das minorias (2), saúde (3), política interna e justiça (12), política social (13) e governo e administração pública (20) (Jennings et al., 2011). Esses resultados corroboram a expectativa teórica de que a prevalência de um tópico está alinhada às preferências partidárias. Pode-se ainda dizer que a agenda política era, em grande parte, uma agenda "de esquerda" quando compara-se, por exemplo o tópico de governo (20) com política externa (19). Entretanto, comparando os três primeiras tópicos, política social $(4,1 \%)$, política interna e justiça $(4,5 \%)$, e política externa $(5,4 \%)$, uma maior atenção é dada ao último deles, apesar da pequena diferença percentual. O que isso quer dizer? Há evidências de que os manifestos partidários se tornam mais complexos, em termos de tópicos apresentados, com o passar do tempo (Green-Pedersen, 2007). Isso denota que, quando o presidente falou de política externa, que é um tópico que seria típico de conservadores - de acordo com o estudo mencionado acima -, ele estava realmente se referindo a uma crítica, por exemplo, ao sistema capitalista internacional ou à necessidade da união dos países sul-americanos, duas políticas alinhadas a ideologia de esquerda. Ao fazer uma análise mais profunda, no entanto, pode-se dizer que as agendas executivas foram em grande parte retóricas, o que é uma constatação inovadora em comparação com outros estudos sobre agendamento.

Indo um pouco mais a fundo, o que o presidente quer dizer quando fala das duas questões, consideradas "de esquerda", com as maiores porcentagens, e o que exatamente ele diz quando usa retórica? A atenção aos direitos e liberdades civis e das minorias é particularmente elevada em seus discursos quando comparada a outros tópicos. Essa atenção pode ser observada no decorrer dos 10 anos de governo. Durante os primeiros anos (2007-2009) de sua presidência, Correa discursou sobre a migração equatoriana e como ele trabalharia para os migrantes equatorianos através da representação legislativa e da Secretaria Nacional de Migração. Durante sua segunda presidência (2009-2013), a atenção a esse tema, particularmente no discurso de 2011, cresceu abruptamente porque ele se concentrou nas questões de liberdade de expressão e defendeu o direito à honra e a dignidade. Isso ocorreu, em grande parte, devido à luta constante que o presidente teve com a mídia e seus oponentes e, na interpretação do ex-presidente, da aliança entre esses dois últimos. O que aconteceu na época? Correa apresentou uma queixa em março de 2011 acusando o jornalista Emilio Palacio e os três diretores do diário "El Universo" do crime de difamação contra uma autoridade pública por causa de um artigo de opinião do jornal. O artigo "Não à mentira", refere-se a Correa como "o Ditador". Palacio acusou Correa de "ter ordenado abrir fogo à vontade, e sem aviso prévio, contra um hospital pleno de civis e inocentes" durante o que o governo considerava ser um golpe, em setembro de 2010. O artigo concluiu: "Crimes contra a humanidade, não esqueçam, não prescrevem”. Em 20 de julho de 2011, um juiz criminal de Guayas condenou o jornalista Emilio Palacio e três diretores do jornal "El Universo" a três anos de prisão. (El Universo, 2012). Durante sua terceira presidência (2013-2017), a atenção sobre esse assunto cresceu. Em 2014, por exemplo, o discurso enfatizou fortemente a maneira como o governo trabalha para a nãodiscriminação contra as mulheres e o respeito pelas comunidades LGBTI. 
A atenção ao tópico sobre o governo e a administração pública sempre é alta nos discursos, quando comparado aos demais tópicos do livro de códigos. Essas questões foram mais pronunciadas nos anos anteriores à Constituição de 2008; depois disso, elas diminuem e finalmente se estabilizam. Isso ocorre porque na primeira presidência, Correa baseou seu discurso na necessidade de um referendo para formar uma Assembleia Nacional Constituinte e depois se concentrou em justificar o trabalho dessa nova assembleia até que uma nova Constituição fosse promulgada, propondo um novo Estado. Durante sua segunda presidência (2009-2013), especialmente em 2011, os discursos se concentraram no referendo de 7 de maio sobre questões relacionadas ao sistema judiciário, à segurança, ao meio ambiente, aos serviços bancários e à mídia, que acabariam por favorecer a posição do governo. Finalmente, durante a terceira presidência (2013-2017), a atenção sobre esse tópico (por exemplo, em 2015) diz respeito ao modelo democrático da revolução cidadã, o projeto político do ex-presidente que beneficia a grande maioria.

No entanto, o código "retórica" tem a maior porcentagem de atenção. Seus exemplos ao longo dos dez anos de discursos envolvem o uso de metáforas em torno de todos os temas: a narração de contos e mitos heroicos, especialmente aqueles sobre independência, referindo-se às batalhas militares de Bolívar, Sucre e outras figuras históricas; frases, poemas e citações textuais de outros autores, como quando o ex-presidente citou poemas para dizer que não se sentia ferido; slogans governamentais como "que tudo seja roubado, exceto a esperança”; frases clichês de figuras políticas tradicionais, como "Hasta la Victoria siempre” de Che Guevara. O código 'retórica' deve ser preservado entre as evidências e comparado com os demais. Sua importância é que ele permeia todo o corpo de discursos e está relacionado tanto com as coisas que o ex-presidente defendeu, quanto com as coisas que ele atacou em seus discursos.

Em segundo lugar, testamos se Correa deu atenção às questões centrais do executivo. Seria de esperar que os dados coletados mostrassem que a agenda presidencial abordou aspectos como economia, questões de governo e administração pública, política externa, política interna e justiça e questões de defesa, todas ligadas às funções do Estado. Para avaliar a diversidade de temas nos discursos presidenciais, traçamos a Figura 2.

FIGURA 2 ENTROPIA (H) DOS DISCURSOS AO LONGO DE 10 ANOS

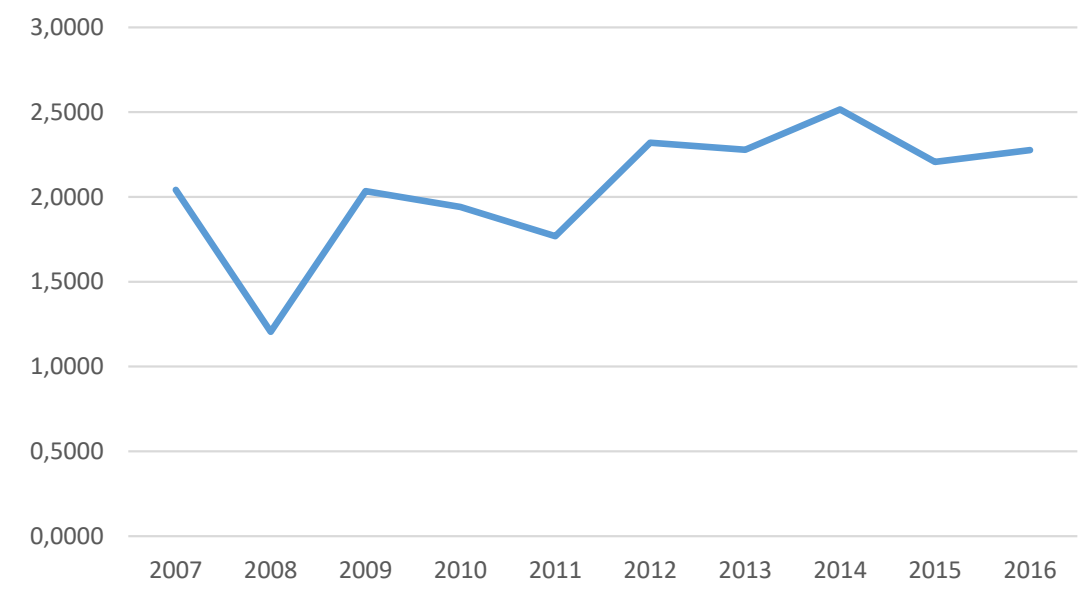

Fonte: Elaborada pelo autor em base aos discursos de Rafael Correa entre 2007 e 2016. 
A análise dos efeitos de tópicos específicos sobre a diversidade da agenda executiva, revela um padrão que é consistente com a teoria. $\mathrm{O}$ efeito sobre a diversidade da agenda é significativo em três dos cinco principais tópicos associados às funções centrais do Estado: questões macroeconômicas (1), política externa (19) e governo e administração pública (20). Essa significância mostra que a intensificação da atenção executiva a cada um desses tópicos leva à redução da diversidade da agenda. Em outras palavras, as funções centrais do governo tendem a tomar a atenção do governo em relação aos outros tópicos, levando a uma diminuição na diversidade da agenda. Quando o governo atende a essas questões centrais, a parcela de sua atenção disponível para alocar a outros tópicos cai. A maior redução na diversidade foi observada em 2008 (1.2057) quando o discurso do presidente enfatizou que era necessário que a Assembleia Constituinte chegasse a um acordo sobre uma nova constituição. Combinando esses dados com a Figura 1, podemos ver que quando a agenda se concentra nos tópicos 'governo' (20) e 'retórica' (ambas com 41,8\% de atenção, ou seja, ocupando 83,6\% da agenda), os tópicos como economia e política externa, que também são questões centrais à função do Estado, são omitidas e não ganham nenhuma porcentagem de atenção.

Em contraste, o ano de 2014 (2.516) indica um aumento na diversidade. Isso sugere que, além das questões centrais do Estado, tópicos como educação (6) e direitos (2) ganharam espaço na agenda política. Combinando esses dados com a Figura 1, podemos ver que quando a agenda é diversificada devido a uma redução na atenção dada a questões centrais como o tópico de governo e administração pública $(22,2 \%)$, economia $(6,8 \%)$, política externa $(9,2 \%)$ e até retórica $(13,4 \%)$, questões como direitos $(9,7 \%)$ e educação $(10,4 \%)$ ganham atenção. No caso da educação o governo quis enfatizar quanto dinheiro foi alocado do orçamento para a educação, a criação de novas universidades, e concursos para novos professores, entre outros. Essas conclusões são consistentes com os estudos realizados sobre os discursos realizados no âmbito da União Europeia.

Em terceiro lugar, em relação a eventos não planejados e externos, espera-se que os dados coletados mostrem que o surgimento desses tópicos causa um impacto na agenda política do ex-presidente. Em relação às questões econômicas (1), um dos primeiros eventos a ser considerado seria a crise econômica de 2008; no entanto, o tópico não teve aumento de atenção no discurso. Em sua fala em janeiro de 2008, o presidente não considera a economia como importante. Ele se concentra em questões de governo. Em 2009, os aspectos econômicos aparecem em baixas porcentagem, mas o discurso não se refere à crise; ao contrário, baseia-se na posição política do modelo econômico do governo, no qual os seres humanos são elevados acima do capital. Assim, parece que as preferências do ex-presidente são mais importantes do que os eventos externos.

Finalmente, em relação a outras questões como o clima (27), o código que descreve tópicos relacionados a desastres naturais entra na agenda política do presidente no discurso de 2016. Isso ocorre porque no dia 16 de abril de 2016, às $18 \mathrm{~h} 58$, um terremoto de magnitude 7,8, com origem em uma região a $20 \mathrm{~km}$ da costa e epicentro na cidade de Muisne (localizado entre Cojimíes e Pedernales), matou cerca de 663 pessoas: 9 desapareceram, 6.274 ficaram feridas e 28.775 foram desalojadas. Cerca de 113 pessoas foram resgatadas vivas dos escombros (Secretaría de Gestión de Riesgos de Ecuador, 2016). Esse evento externo teve um papel importante em definir parte da agenda executiva naquele momento. 


\section{CONCLUSÕES}

Esse artigo investigou a agenda política do ex-presidente do Equador Rafael Correa Delgado por meio das teorias e métodos aplicados pelas equipes do Comparative Agenda Project (CAP) na Europa e nos Estados Unidos, buscando explicar porque algumas questões são mais importantes do que outras e porque os tópicos variam com o tempo. Quais são os fatos interessantes que podemos aprender com o caso do Equador, particularmente em relação à pesquisa sobre o agendamento da política pública?

Primeiro, verificamos que as questões mais importantes coincidem com aquelas que geralmente são destacadas por partidos não conservadores, como os temas relacionados ao governo e a administração pública, ou por partidos de esquerda, como direitos em geral. É importante ressaltar que tópicos considerados tradicionalmente como 'de direita' ou 'conservadores', foram também observados em algum momento na agenda. Assim, as preferências partidárias são importantes no Equador, mas também são complexas e não representam necessariamente a diferença tradicional entre esquerda $\mathrm{e}$ direita. O estudo revelou um código prevalente - chamado aqui de "retórica" - que concentrou uma boa parte da atenção da agenda do executivo do país, e que não havia sido considerado na literatura. Assim, pesquisas futuras também devem avaliar o impacto desse novo código, observando-o a partir de uma perspectiva de ressonância cultural (Entman, 1993), ou do ponto de vista da retórica em relação a análise do discurso. Algumas indagações que podem orientar novas investigações: Será que o objetivo desse discurso é simplesmente facilitar a conexão da liderança política com o público alvo, sem uma preocupação de cunho técnico ou racional? Será que tal retórica é um denominador comum, ou seja, faz parte das preferências dos partidos de esquerda na América Latina?

Em segundo lugar, a agenda política do ex-presidente segue a lógica de que as funções centrais prevalecem em comparação com outras, o que significa dizer que são contemplados tópicos relacionados ao governo e administração pública, políticas internas e justiça, economia e política externa, como demonstrado em Jennings et al. (2011). Entretanto, não há um foco relevante no tema 'defesa', diferente do observado nos estudos de caso envolvendo países europeus. Uma explicação para isso pode ser o fato de que o tema da defesa, em relação a potencial agressão recebida da parte de outras nações, não é uma preocupação na América Latina - diferente do que observado na Europa, em que essa perspectiva de defesa é uma função central. Nos países latino-americanos, a questão da defesa está mais relacionada a estabilidade política. Eis aqui outra linha de investigação para futuros estudos.

Um terceiro ponto a se destacar é que os eventos externos são importantes e acabam encontrado espaço na agenda política. O terremoto de 2016, por exemplo, fez retornar a agenda o tópico 'clima' (27), que estava ausente e retornou ocupando uma parte considerável da atenção do executivo.

Por fim, esse trabalho empírico é uma primeira incursão num estudo mais amplo da agenda política equatoriana que examinará a atual legislação e a cobertura da mídia para verificar se as teorias e hipóteses aplicadas nos EUA e na Europa fazem sentido no país e, claro, abrir as portas para possíveis pesquisas comparativas entre o Equador e outras nações latino-americanas. Os resultados e ideias discutidos aqui levantam algumas outras perguntas a explorar futuramente, por exemplo: a relevância do código "retórica" reflete uma agenda populista, de esquerda ou presidencial? Outras teorias aplicadas nos EUA e na União Europeia são também aplicáveis em países latino-americanos, como o Equador? 


\section{REFERÊNCIAS}

Bachrach, P., \& Baratz, M. S. (1962). Two faces of power. American political science review, 56(4), 947-952.

Baumgartner, F. R., \& Jones, B. D. (2010). Agendas and instability in American politics. University of Chicago Press.

Baumgartner, F. R., \& Jones, B. D. (2015). The politics of information: Problem definition and the course of public policy in America. Chicago, IL: University of Chicago Press.

Baumgartner, F. R., Jones, B., \& MacLeod, M. C. (1998). Lessons from the trenches: Quality, reliability, and usability in a new data source. The Political Methodologist, 8(2), 1-11.

Baumgartner, F. R., Jones, B. D., \& Wilkerson, J. (2011). Comparative studies of policy dynamics. Comparative Political Studies, 44(8), 947-972.

Boix, C. (1998). Political Parties, Growth and Equality: Conservative and Social Democratic Economic Strategies in the World Economy. Cambridge, UK: Cambridge University Press.

Boydstun, A. E., Bevan, S., \& Thomas III, H. F. (2014). The importance of attention diversity and how to measure it. Policy Studies Journal, 42(2), 173-196.

Breeman, G., Lowery, D., Poppelaars, C., Resodihardjo, S. L., Timmermans, A., \& De Vries, J. (2009). Political attention in a coalition system: Analyzing Queen's speeches in the Netherlands 1945-2007. Acta Politica, 44(1), 1-1.

Budge, I., \& Farlie, D. (1983). Party competition: selective emphasis or direct confrontation? an alternative view with data. In H. Daalder, \& P. Mair (Eds), Western European party systems: continuity \& change (pp. 267-305). London, UK: SAGE Publications.

Budge, I., \& Hofferbert, R. I. (1990). Mandates and policy outputs: US party platforms and federal expenditures. American Political Science Review, 84(1), 111-131.

Canes-Wrone, B. (2001). A theory of presidents' public agenda setting. Journal of Theoretical Politics, 13(2), 183-208.
Carmines, E. G., \& Stimson, J. A. (1989). Issue evolution: Race and the transformation of American politics. Princeton, NJ: Princeton University Press.

Chaqués-Bonafont, L., Baumgartner, F. R., \& Palau, A. (2015). Agenda dynamics in Spain. New York, NY: Springer.

Chaqués-Bonafont, L., Palau, AM, Muñoz, L. y Wilkerson, J. (2008). Comparación de agendas gubernamentales: Evolución de la priorización de problemas en Estados Unidos y España.

Cobb, R. W., \& Elder, C. D. (1980). Participation in American politics: The dynamics of agenda-building. Baltimore, Maryland: Johns Hopkins University Press.

Cohen, J. E. (1999). Presidential responsiveness and public policy-making: The publics and the policies that presidents choose. Ann Arbor, Michigan: University of Michigan Press.

Dowding, K., Hindmoor, A., Iles, R., \& John, P. (2010). Policy agendas in Australian politics: The governor-general's speeches, 1945-2008. Australian Journal of Political Science, 45(4), 533-557.

Downs, A. (1972). Up and down with ecology-the "issue-attention cycle". National Affairs, 44, 38-50.

Edwards III, G. C., \& Barrett, A. (2000). Presidential Agenda Setting in Congress. In J. R. Bond, \& R. Fleisher (Eds.), Polarized Politics: Congress and the President in a Partisan Era. Washington, DC: CQ Press.

El Universo. (2012, fevereiro 17). Cronología del caso el Universo. Recuperado de https://www.eluniverso. com/2012/02/17/1/1355/cronologia-caso-universo. html

Entman, R. M. (1993). Framing: Toward clarification of a fractured paradigm. Journal of communication, 43(4), 51-58.

Green-Pedersen C. (2006). Long-term Changes in Danish Party Politics: The Rise and Importance of Issue Competition. Scandinavian Political Studies, 29(3), 219-235.

Green-Pedersen, C. (2007). The growing Importance of Issue Competion: The Changing Nature of Party Competition in Western Europe. Political Studies, $55,607-628$. 
Green, J., \& Jennings, W. (2012). Valence and Government Priorities: How issue ownership and issue salience shape US and UK policy agendas. In presentation at the Elections, Public Opinion and Parties Conference, Oxford, UK.

Green, J., \& Jennings, W. (2019). Party reputations and policy priorities: How issue ownership shapes executive and legislative agendas. British Journal of Political Science, 49(2), 443-466.

Green-Pedersen, C., \& Mortensen, P. B. (2010). Who sets the agenda and who responds to it in the Danish parliament? A new model of issue competition and agenda-setting. European Journal of Political Research, 49(2), 257-281.

Hobbes, T. (1651). Leviathan. London, UK: Bloomsbury Publishing.

Jennings, W., \& John, P. (2009). The dynamics of political attention: Public opinion and the queen's speech in the United Kingdom. American Journal of Political Science, 53(4), 838-854.

Jennings, W., Bevan, S., \& John, P. (2011). The agenda of British government: The speech from the throne, 1911-2008. Political Studies, 59(1), 74-98.

Jennings, W., Bevan, S., Timmermans, A., Breeman, G., Brouard, S., Chaqués-Bonafont, L\& Palau, A. M. (2011). Effects of the core functions of government on the diversity of executive agendas. Comparative Political Studies, 44(8), 1001-1030.

John, P. (2006). The policy agendas project: a review. Journal of European Public Policy, 13(7), 975-986.

John, P., Jennings, W., \& Bevan, S. (2010, April). Large Changes in the Agenda of the UK Government, 1911-2008: Identifying and Analyzing Policy Punctuations. In Proceedings of UK Political Studies Association annual conference, Edinburgh, Scotland.

John, P., Larsen, H. P., \& Liu, H. (2006). Comparing Executive-led Policy Agendas in the USA and UK. In Proceedings of annual meeting of the Midwest Political Science Association, Chicago, IL.

Jones, B. (2001). Politics and the Architecture of Choice. Chicago, IL: University of Chicago Press.

Jones, B. D., \& Baumgartner, F. R. (2005). The politics of attention: How government prioritizes problems. Chicago, IL: University of Chicago Press.
Jones, B. D., Sulkin, T., \& Larsen, H. A. (2003). Policy punctuations in American political institutions. American Political Science Review, 97(1), 151-169.

Kingdon, J. W., \& Stano, E. (1984). Agendas, alternatives, and public policies (Vol. 45, pp. 165-169). Boston, MA: Little Brown.

Klingemann, H. D., Hofferbert, R. I., \& Budge, I. (1994). Parties, policies, and democracy. Boulder, Colorado: Westview.

Locke, J. (1689). Two Treatises of Government. London, UK: Awnsham Churchill.

Maravall, J. (1999). Accountability and manipulation. In A. Przeworski, S. C. Stokes, \& B. Manin. (Eds.), Democracy, Accountability and Representation. Cambridge, UK: Cambridge University Press.

McCombs, M. E., \& Shaw, D. L. (1972). The agendasetting function of mass media. Public opinion quarterly, 36(2), 176-187.

Mortensen, P. B., Green-Pedersen, C., Breeman, G. E., Chaqués-Bonafont, L. , Jennings, W., John, P.... \& Timmermans, A. (2009). Comparing government agendas: executive speeches in the Netherlands, United Kingdom, Denmark and Spain. In Proceedings of $2^{\circ}$ Annual Meeting of the Comparative Policy Agendas Conference, The Hague, The Netherlands.

Mortensen, P. B., Green-Pedersen, C., Breeman, G., Chaqués-Bonafont, L., Jennings, W., John, P.... \& Timmermans, A. (2011). Comparing government agendas: Executive speeches in the Netherlands, United Kingdom, and Denmark. Comparative Political Studies, 44(8), 973-1000.

Petrocik, J. R. (1996). Issue ownership in presidential elections, with a 1980 case study. American journal of political science, 825-850.

Rousseau, J. J. (1762). The Social Contract. France, Paris: Penguin Books.

Schnattschneider, E. E. (1960). The semisovereign people. New York, NY: Holt, Reinhart and Winston.

Secretaría de Gestión de Riesgos de Ecuador. (2016). Informe de situación $N^{\circ} 71$-Terremoto 7.8 Pedernales. Recuperado de https://www.gestionderiesgos. gob.ec/wp-content/uploads/downloads/2016/05/ INFORME-n71-SISMO-78-20302.pdf 
Shannon, C. E. (1948). A mathematical theory of communication. Bell system technical journal, 27(3), $379-423$.

Volkens, A. (2002). Manifesto Coding. Berlin, Germany: WZB.
Walgrave, S., Varone, F., \& Dumont, P. (2006). Policy with or without parties? A comparative analysis of policy priorities and policy change in Belgium, 1991 to 2000. Journal of European Public Policy, 13(7), 1021-1038.

\section{Pablo Ruiz Aguirre}

https://orcid.org/0000-0002-1504-7544

M.Sc. em Governança, Políticas Públicas e Economia Política; Professor Associado na Facultad de Jurisprudencia da Universidad Internaconal del Ecuador (UIDE). E-mail paruizag@uide.edu.ec 